\title{
RELACIONES COLECTIVAS DE TRABAJO Y SU ROL EN LA PROTECCIÓN DEL MEDIO AMBIENTE
}

\author{
COLLECTIVE LABOR RELATIONSHIPS AND THEIR ROLE IN \\ THE PROTECTION OF THE ENVIRONMENT
}

PAULINA ALVARADO BARRIENTOS*

\section{RESUMEN}

Trabajo y medio ambiente son conceptos aparentemente disociados. Este artículo tiene por objeto desmitificar tales apariencias separatistas, basándonos principalmente en el estudio del derecho comparado, para luego concatenar elementos comunes que inciden en las relaciones laborales y que asignan particularmente a las organizaciones sindicales un rol activo en la protección del medio ambiente. Ello, sin perder de vista el análisis crítico sobre nuestra legislación y los desafíos que nos depara el futuro del Derecho del Trabajo.

Palabras clave: Relaciones colectivas del trabajo, Medio ambiente, Protección del medio ambiente, Sindicatos, Negociación colectiva, Derecho del Trabajo.

\footnotetext{
* Abogada, Licenciada en Ciencias Jurídicas y Sociales, Universidad de Magallanes. Magíster en Derecho del Trabajo y Previsión Social, Universidad de Concepción. Profesora de Derecho del Trabajo y Seguridad Social de la Universidad de Magallanes, Punta Arenas, Chile. Correo electrónico: paulina. alvarado@umag.cl. ORCID: https://orcid.org/0000-0001-5831-5564.
}

Artículo recibido el 19 de octubre de 2020, y aprobado para su publicación el 20 de junio de 2021. 


\section{ABSTRACT}

Labor and environment are apparently dissociated concepts. The purpose of this article is to demystify such separatist appearances, based mainly on the study of comparative law, to later concatenate common elements that affect the relationships at work and that particularly assigns trade union organizations an active role in protecting the environment. This, without losing sight of the critical analysis of our legislation and the challenges that the future of Labor Law holds for us.

Keywords: Collective labor relations, Environment, Environmental protection, Trade unions, Collective bargaining, Labor law.

\section{INTRODUCCIÓN}

Esta investigación se centra en el estudio de las medidas que se han dispuesto para propender a que las organizaciones sindicales tengan un rol activo en la protección del medio ambiente. En este contexto, nuestro objetivo principal es formular un análisis descriptivo de las iniciativas internacionales y nacionales que han abordado la materia, para luego analizar el rol que han desempeñado algunos sindicatos de corte independiente ante la jurisdicción ambiental, evidenciando de este modo, la natural compatibilidad que existe entre la protección del medio ambiente y su debido resguardo por los trabajadores.

Luego, analizaremos la experiencia comparada, y las innovaciones normativas que, en materia de medio ambiente y trabajo, han sido adoptadas por la legislación laboral de Francia y España.

Finalmente, nos centraremos en replantear el enfoque de algunas normas jurídicas explícitas contenidas en el ordenamiento jurídico laboral, que precisan ser readecuadas a fin de dar cumplimiento a la protección efectiva del medio ambiente dentro de los espacios laborales. Bajo este contexto nos centramos particularmente en el análisis del derecho de información, las finalidades sindicales y la negociación colectiva. 


\section{DIAGNÓSTICO}

\section{Nivel Internacional}

En el marco del modelo de producción capitalista, naturaleza y el trabajo constituyen elementos que han de ser explotados con el objeto de obtener los máximos beneficios para su apropiación privada. ${ }^{1} \mathrm{Al}$ respecto, resulta de vital importancia realizar un análisis del polinomio trabajo y medio ambiente bajo la sombra del modo de producción en que se desenvuelven ambos factores, a fin de hacer una revisión de sus repercusiones y de las posibles alternativas que pueden ser adoptadas por el Derecho del Trabajo, para mejorar el bienestar de los trabajadores y con ello al medio ambiente.

En la actualidad nos vemos inmersos en un intenso debate, el modelo de desarrollo productivo sobre el que se desenvuelven las relaciones laborales, exige un replanteamiento. Fenómenos tales como: la depredación humana del medio ambiente, el deshielo de los glaciares, y el aumento del nivel del mar - por nombrar algunos - han acelerado el avance de los efectos del cambio climático y con ello está en riesgo el sustento del trabajo como acción humana, y el medio ambiente como hábitat genuino de nuestra especie.

Desde el año 1983, momento en que la crisis ecológica del planeta se hacía cada vez más evidente, la Asamblea General de las Naciones Unidas dispuso la creación de una comisión internacional (Comisión Mundial para el Desarrollo del Ambiente) con el fin de realizar un diagnóstico de la situación ambiental del planeta. El informe, denominado "Nuestro Futuro Común", fue entregado en el año 1987 y ha sido conocido como el Informe Brundtland. El citado documento, fue el insumo que más tarde se utilizó para la Cumbre de la Tierra que se realizó en Río de Janeiro en el año 1992.

El informe Brundtland evidenció los graves problemas ambientales que padecía el planeta. Sin embargo, en él no se planteó la exploración de opciones fuera del marco centrado en la lógica del crecimiento económico, muy por el contrario, la solución que fluye del documento es similar a la que otorgan hasta la fecha organismos internacionales tales como: Naciones Unidas y la Organización Internacional del Trabajo, (en adelante OIT), al sostener que la mejor forma de responder a los retos planteados por la

\footnotetext{
${ }^{1}$ Polanyi, Karl, La gran transformación, Editorial Quipu, Madrid, 2007, p. 291.
} 
destrucción ambiental y la pobreza, es mediante más crecimiento. ${ }^{2}$

Por su parte, en el año 2007, el Director General de la Organización Internacional del Trabajo, examinó la relación entre trabajo decente y cambio climático, refiriéndose por primera vez al concepto de empleos verdes. ${ }^{3}$ Más tarde se puso en marcha dicha iniciativa con la colaboración del Programa de las Naciones Unidas para el medio ambiente (PNUMA), la Confederación Internacional Sindical (CSI), la Organización Internacional de Empleadores (OIE), y la Organización Internacional del Trabajo (OIT) con el fin de movilizar a los gobiernos e intervinientes de las relaciones laborales y establecer diálogos en torno a la adopción de políticas coherentes y programas eficaces que conduzcan a una economía verde, con empleos verdes y trabajo decente para todos.

En la misma instancia precedente el Director de la OIT de aquel entonces manifestó: "es en la empresa y los lugares de trabajo donde las dimensiones social, económica y medioambiental son indisociables". ${ }^{4} \mathrm{La}$ conjunción de tales elementos, adquiere sentido en la medida en que cada uno de ellos se unifican al interior de los espacios laborales.

A pesar de los esfuerzos de los organismos internacionales, hoy existen un sinnúmero de fuentes de trabajo en el mundo que se encuentran amenazadas por la aceleración de los efectos del cambio climático: la agricultura, silvicultura y la pesca, funciones laborales que emplean a más de mil millones de personas. A modo de ejemplo: la agricultura, es la fuente laboral que emplea mayor cantidad de personas pobres y comparte el triste record de ser la causante de las mayores emisiones de gases de efecto invernadero, el principal usuario de recursos hídricos, y los mayores responsables de la degradación de la tierra y la pérdida de biodiversidad. ${ }^{5}$

Puede apreciarse que desde el informe Brundtrland (1983) al Plan de Desarrollo Sostenible de la OIT (2007), se plantea que, con los mismos mecanismos de mercado y patrones científicos y tecnológicos, con la misma

\footnotetext{
${ }^{2}$ LANDER, Edgardo, "El lobo se viste con piel de cordero", Revista América Latina en movimiento, 2011, II Edición, p.3.

${ }^{3}$ Según la Organización Internacional del Trabajo, los empleos verdes son empleos decentes que contribuyen a preservar y restaurar el medio ambiente ya sea en los sectores tradicionales como la manufactura o la construcción o en nuevos sectores emergentes como las energías renovables y la eficiencia energética.

${ }^{4}$ Organización Internacional del Trabajo (OIT), “Conclusiones relativas a la promoción de empresas sostenibles”, Conferencia Internacional del Trabajo, 96ª reunión, 2007, párrafos 3 y 8.

${ }^{5}$ OIT, cit. (n. 4), p. 14.
} 
lógica del crecimiento sostenido, será posible salvar la vida en el planeta. No obstante, algunos proyectan que el modelo de desarrollo capitalista busca la manera de entender la crisis ecológica, ambiental, energética y alimentaria que ha suscitado, pero la ve siempre desde un punto de vista de ganancia, ${ }^{6}$ no alberga la concepción de dignidad humana y mucho menos ambiental. Parece ser que el modelo no plantea como solución, la disminución del consumo, sino la entrega de productos y servicios "más o menos verdes", esto es en lo que precisamente se basa la sustentabilidad y sostenibilidad.

En la Conferencia del Centenario de la OIT para el futuro del trabajo (2019), se declaró que "el mundo del trabajo se está transformando radicalmente impulsado por las innovaciones tecnológicas, los cambios demográficos, el cambio medioambiental y climático y la globalización, así como en un momento de desigualdades persistentes, que tienen profundas repercusiones en la naturaleza y el futuro del trabajo y en el lugar y la dignidad de las personas que se encuentran en dicho contexto". ${ }^{7}$ Nuevamente constatamos que la naturaleza y todo lo que el concepto involucra sigue siendo una preocupación inserta en el mundo del trabajo que representa desafíos que exigen de los Estados partes e intervinientes de la relación laboral, tomar medidas que estén a la altura de los riesgos ambientales que amenazan la vida del planeta.

Loanterior, hatraído como corolario quelos organismosinternacionales, entre ellos la OIT y el Departamento de Asuntos Económicos y Sociales de las Naciones Unidas ubiquen en el Programa 21, capítulo 29 a los trabajadores como principales interesados en el desarrollo sostenible. Así las cosas, la red de colaboración existente entre los sindicatos y el gran número de afiliados constituye una vía importante para encauzar las medidas de apoyo a los conceptos y prácticas a favor del desarrollo sostenible. Entre las medidas, que se proponen en el citado instrumento se incorpora: 1) incrementar el número de convenios ambientales colectivos, y 2) incrementar medidas relativas a la educación, capacitación y readecuación de trabajadores, especialmente, en materias asociadas al medio ambiente.

\footnotetext{
${ }^{6}$ LEÓN, Osvaldo, "Economía verde: la conciencia máxima del capitalismo", Revista América Latina en movimiento, 2011, II Ed., p. 7.

${ }^{7}$ Conferencia Internacional del Trabajo, "Declaración del Centenario de la OIT para el futuro del trabajo", https://www.ilo.org/wcmsp5/groups/public/---ed_norm/---relconf/documents/meetingdocument/ wcms_711699.pdf, consultada: 20 de febrero de 2020.
} 


\section{Nivel Nacional}

La intención de configurar una alianza entre medio ambiente y trabajo con carácter más omnicomprensivo surgió a partir del Convenio $\mathrm{N}^{\circ} 155$ (1981) de la Organización Internacional del Trabajo, en él se evidencia el hecho de que la salud de los trabajadores trasciende a una esfera que va más allá del espacio físico de la empresa, obligando a los intervinientes (Estado - empleadores - trabajadores) a tener un rol de participación más activo en la toma de decisiones de carácter ambiental que se susciten al interior del recinto laboral. No obstante dicho convenio a la fecha, no ha sido ratificado por nuestro país, dado que Chile sólo se ha acotado a ratificar convenios de carácter más específico y de contenidos que mantienen la tónica reactiva y preventiva frente a la exposición de riesgos ambientales de los trabajadores, así por ejemplo: el Convenio $\mathrm{N}^{\mathrm{o}} 162$ sobre la exposición de trabajadores al asbesto, Convenio $\mathrm{N}^{0} 136$ sobre la exposición de trabajadores al benceno, Convenio $\mathrm{N}^{\mathrm{o}} 115$ sobre la protección contra las radiaciones, entre otros.

El Convenio $\mathrm{N}^{\circ} 155$ de la OIT, sobre seguridad y salud de los trabajadores en el medio ambiente del trabajo, es un instrumento particularmente idóneo a la hora de entrelazar cuestiones medio ambientales con el derecho a la salud laboral de las personas, pues tal instrumento incide en el establecimiento de una cultura de derechos respetuosa por las operaciones, procesos y entorno del trabajador. ${ }^{8}$

Al margen del plano internacional, en nuestro país el resguardo del medio ambiente se encuentra vinculado a la existencia de una institucionalidad ambiental formada por diversos organismos, entre ellos, los Tribunales Ambientales con presencia en Antofagasta, Santiago y Valdivia creados en el año 2012 bajo el alero de la Ley $N^{\circ}$ 20.600. A ello debemos agregar la Ley No 19.330 sobre Bases Generales del Medio Ambiente y a su turno, el Art. $19 \mathrm{~N}^{\circ} 8$ de la Constitución Política de la República asegura a todas las personas el derecho de vivir en un medio ambiente libre de contaminación, para lo cual, el Estado debe velar por que este derecho no se vea afectado y tutelar la preservación de la naturaleza. Según TISNE, ${ }^{9}$ la tutela del medio

\footnotetext{
${ }^{8}$ Chacartegui, Consuelo, Negociación colectiva y sostenibilidad medioambiental, Editorial Bomarzo, Albacete, 2018, pág. 100.

${ }^{9}$ TISNE, Jorge, "Los intereses comprometidos en el daño ambiental. Comentario al nuevo procedimiento por daño ambiental de la Ley No 20.600", Revista de Derecho de la Universidad Católica del Norte, 2014, No 1204, p. 325.
} 
ambiente contiene una naturaleza colectiva en su ejercicio por cuanto su uso o disfrute es ejercido por todos, y por otro lado su deterioro puede afectar a un número indeterminado de personas.

Igualmente, la estructura normativa del derecho a vivir en un medio ambiente libre de contaminación supone la custodia de un derecho supraindividual que ha sido definido por Aguirrezabal, como: "Aquel que significa que trasciende la esfera de lo meramente individual, está marcado por la impersonalidad y rompe con el concepto clásico de derecho subjetivo". ${ }^{10}$

Lo anterior, reafirma que la titularidad de este bien jurídico no sólo corresponde al directamente afectado sino también a un colectivo. Desde este punto de vista, cobra especial relevancia el quehacer sindical en la materia, desde que a través de la doctrina, y la jurisprudencia, como veremos más adelante, se ha construido una alternativa jurídico procesal viable que ha habilitado a ciertas organizaciones - como legitimarios activos - para la interposición en primer término del recurso de protección y luego de la acción de reparación ambiental respecto de aquellos hechos que afecten el denominado territorio adyacente de ciertos grupos intermedios, ${ }^{11}$ todo ello bajo el alero de lo prescrito en el artículo 54 de la Ley 19.300 sobre Bases Generales del Medio Ambiente. ${ }^{12}$

\footnotetext{
${ }^{10}$ Aguirrezabal, Maite, "Algunas consideraciones en torno a los intereses supraindividuales (colectivos y difusos)", Revista Chilena de Derecho, 2006, Vol. 33 No 1, p. 74.

${ }^{11}$ En este sentido el autor TiSNE, Jorge, "Las organizaciones ciudadanas como representantes de intereses colectivos ambientales. Reconocimiento a través de la Jurisprudencia Chilena", Revista de Derecho - P. Universidad Católica de Valparaíso, 2016, pp. 234-236. Realiza un interesante análisis jurisprudencial acerca del reconocimiento que tienen ciertas organizaciones ciudadanas para actuar en defensa del medio ambiente a través del Recurso de Protección, refiriéndose por ejemplo al caso "Trillium", empresa que pretendía desarrollar una actividad de tala y explotación de lenga en la Provincia de Tierra del Fuego; o al caso del Grupo de Acción Ecológica de Chinchimén y el Consejo Ecológico de las comunas de Puchuncaví y Quintero que interpusieron un recurso de protección en contra de una resolución de la Comisión Regional de Medio Ambiente de Valparaíso que calificó favorablemente el estudio de impacto ambiental del proyecto Central Termoeléctrica Campiche.

${ }^{12}$ El inciso $1^{\circ}$ del artículo 54 de la Ley $N^{\circ} 19.300$ sobre Bases Generales del Medio Ambiente, consagra expresamente la acción de daño ambiental con fines reparatorios para el medio ambiente a las personas naturales o jurídicas, públicas o privadas, que hayan sufrido el daño o perjuicio, las municipalidades, por los hechos acaecidos en sus respectivas comunas.
} 
III. PROPUESTAS PARA FAVORECER LA ARMONIZACIÓN JURÍDICA ENTRE TRABAJO Y MEDIO AMBIENTE

\section{Ciudadano-trabajador del medio ambiente.}

El fenómeno de la constitucionalización ha sido ampliamente reconocido por la doctrina. El Derecho del Trabajo no es una rama ajena a este contexto, desde el siglo XX a la fecha su evolución se ha visto marcada por la aplicación directa de normas constitucionales a las relaciones entre particulares. Esta tendencia data del Derecho Continental Europeo en que se gesta el semillero que concibe al trabajador como ciudadano, en virtud de la doctrina denominada "Horizontalwirkung" (horizontalidad de derechos), plasmada también en nuestra legislación laboral, a través del concepto de ciudadanía de la empresa incorporado en el artículo $5^{\circ}$ del Código del Trabajo y cuya ejecución se plasma en el artículo 485 del mismo texto legal.

En materia laboral y en lo que respecta a la búsqueda de una real colaboración de los trabajadores en cuanto a evitar actividades que puedan devenir en un menoscabo al medio ambiente, sería necesario crear mecanismos de denuncias para aquellos incumplimientos de las normas medioambientales de las que los trabajadores pudieran ser testigos o inclusive partícipes, sin que, de ello se generen represalias por parte de la empresa. Es decir, se trataría de intentar asegurar al trabajador una capacidad de actuación como "ciudadano del ambiente en la empresa"13 para lo que sería imprescindible extrapolar los principios que presiden la protección del medio ambiente al interior de la empresa, como el principio de precaución y a su vez, que el mismo genere sinergia y armonía con los derechos fundamentales del trabajador.

En definitiva, se trataría de proteger una suerte de status de ciudadano medioambiental, independientemente del lugar en el que el trabajador se encuentre, que trascienda los mecanismos puramente contractuales que, en última instancia, no son lo suficientemente eficaces y son susceptibles de generar abusos por parte del empleador. Dicho status requeriría de dos aspectos claramente diferenciados: primero, la atribución de facultades

\footnotetext{
${ }^{13}$ Escribano, Juan, “Trabajo y Medio Ambiente. Perspectivas Jurídico-Laborales”, en: Mora. L; Escribano. J, (Coords.), La Ecología del Trabajo. El Trabajo que Sostiene la Vida, Editorial Bomarzo, Albacete, 2015, p. 141.
} 
al trabajador en el control del cumplimiento de las normas de protección del medioambiente; y segundo que dicha atribución venga rodeada de la concesión de garantías para el trabajador que las ejercite. ${ }^{14}$

La vinculación entre trabajador y medio ambiente, dotada de facultades precautorias y fiscalizadoras (indemnidad ambiental), encuentra su mayor desarrollo en el Derecho Francés, a razón de las medidas que se tomaron a consecuencia del accidente ocurrido en la fábrica de fertilizantes AZF en el año 2001. ${ }^{15}$ A raíz de ello, se planteó la necesidad de otorgar a los trabajadores un papel más activo en el control de la producción potencialmente lesiva contra el medio ambiente de sus respectivas empresas. Se partía del deber de colaboración de los trabajadores en la prevención o abstención de aquellas actividades que pueden conllevar un menoscabo al medio ambiente, habría de implicar también la atribución de facultades de denuncia de aquellos incumplimientos de las normas medioambientales de las que los trabajadores pudieran ser testigos, sin que de ello se derivaran represalias por parte de la empresa.

A razón de lo anterior en el año 2013, nace en Francia la ley que crea las alertas ambientales (Ley de independencia de los expertos en salud y medio ambiente y la protección de los denunciantes). Este es un nuevo derecho de alerta que no debe confundirse con el derecho a alertar y retirarse en caso de peligro grave o inminente para la salud del trabajador, consagrado en otro texto (artículo L.4131-1 del Código del Trabajo Francés). El derecho a la alerta ambiental es parte de esta tendencia, que reconoce al empleado como un "ciudadano de la empresa". El nuevo mecanismo autoriza a cualquier trabajador a informar al empleador que los productos, procesos de fabricación utilizados o implementados presentan un "riesgo grave" para la población, la salud o el medio ambiente.

El proceso de alerta, por regla general se registra por escrito, en caso de discordancia entre los denunciantes y el empleador, el asunto puede ser revisado por un representante del Estado. Sin perjuicio de lo interesante que

\footnotetext{
${ }^{14}$ Escribano, Juan, "Derecho de los trabajadores ante las órdenes empresariales medioambientalmente injustas", Revista de Derecho Social, 2017, N 78, p. 15.

${ }^{15}$ El día 20 de septiembre del año 2001, se produjo una explosión en una fábrica de fertilizantes situada a las afueras de Toulouse (Francia) causando 19 muertos y 658 heridos, 50 de ellos de gravedad. Los agentes que participaban en las tareas de socorro no descartaban que pudiera haber más víctimas bajo los escombros. La explosión pudo ser oída a unos 35 kilómetros. El observatorio de Estrasburgo registró el accidente como equivalente a un terremoto de 3,4 en la escala de Richter.
} 
puede ser analizar el procedimiento previsto para estos efectos, llama la atención, que entre los años 2017 y 2020, solo se hayan registrado 12 alertas. Las últimas investigaciones sobre este instituto indican que el derecho a la alerta sanitaria y medioambiental, casi nunca se utiliza por las compañías. ${ }^{16}$

La tragedia en la fábrica y la consecuente elaboración del status de ciudadano ambiental, permitió a Francia dar cumplimiento a la previsión contenida en la Agenda 21 de la Cumbre de la Tierra de Río (1992) en cuya sección 29 se demandaba el fortalecimiento del papel de los trabajadores y de sus sindicatos: "los trabajadores deberían ser plenos participantes en la ejecución y evaluación de las actividades relativas a la Agenda 21".

En tal escenario se aseguró al trabajador una capacidad de actuación para lo que fue imprescindible extrapolar los principios que presiden la protección del medio ambiente al interior de la empresa, en especial, el principio de precaución. De no ser así, el trabajador se vería ante la disyuntiva de no hacer públicos los posibles incumplimientos de la normativa medioambiental en la empresa, ante el riesgo de ser sancionado por ejercitar el papel de ciudadano del ambiente en la empresa. ${ }^{17}$

Otro paso legislativo que contribuyó al ejercicio de la labor fiscalizadora y preventiva de los trabajadores, fue la Ley Francesa 2017/399 del día 27 de febrero del año 2017, sobre el deber de vigilancia de las casas matrices y empresas contratistas. ${ }^{18}$ La ley, que sólo se aplica a las empresas francesas más grandes, establece para ellas la necesidad de analizar y abordar los impactos adversos que sus actividades provocan en las personas y en el planeta, al tiempo que deberán publicar anualmente planes de vigilancia. Estos incluyen los impactos relacionados con sus propias actividades, con aquellas compañías bajo su control directo y los de proveedores y subcontratas, con quienes tengan una relación comercial establecida. ${ }^{19}$

En el marco de la citada ley los sindicatos quedan habilitados como

\footnotetext{
${ }^{16}$ Bugada, Alex, Labour and Environmental Sustainability. French Report, Agreenment, 2020. http:// agreenment.adapt.it/, consultada: 11 de Junio 2021.

${ }^{17}$ Escribano, cit. (n. 14), p. 17.

18 Observatorio de Responsabilidad Social Corporativa, "Francia aprueba la ley sobre el deber de vigilancia de las empresas", https://observatoriorsc.org/francia-aprueba-la-ley-deber-vigilancia-lasempresas/, Consultado: 24 de abril del año 2020.

${ }^{19}$ El artículo 1 de la ley (es decir, el nuevo artículo L. 225-102-4 del Código de Comercio francés) dispone que, cuando una empresa no elabore, publique y aplique efectivamente un plan de vigilancia, cualquier parte con interés en actuar (asociaciones de derechos humanos o ecologistas, sindicatos, etcétera) podrán requerir a dicha empresa que cumpla con sus obligaciones.
} 
agentes de interés para actuar denunciando a la empresa por el incumplimiento del deber de vigilancia sin que con ello queden expuestos a represalias.

Los avances del Derecho Francés suponen un desafío para una legislación como la nuestra, que aún debe sortear diversos obstáculos para alcanzar tales estándares.

Entre los diversos avatares, encontramos la muy discutida aplicación y vigencia del principio precautorio dentro de nuestro ordenamiento jurídico nacional. El contenido de dicho principio ha sido completado por la doctrina ambientalista, a fin de diferenciarlo del principio de prevención. La distinción, posee especial importancia en materia laboral, fundamentalmente en lo tocante a la delimitación de los riesgos que se suscitan durante la prestación de servicios que se realiza en el marco del contrato de trabajo. Los principales matices que diferencian uno de otro, viene dado por el hecho de que el principio precautorio, es el principio básico esencial del Derecho Ambiental, al igual que el principio de prevención, opera sobre las causas y las fuentes de los problemas, de manera integral, holística y totalizadora. La diferencia es que el principio de prevención se encarga sobre el riesgo sabido, conocido, verificado, comprobado, real, en tanto que el de precaución, interviene sobre el riesgo hipotético, sospechoso, el posible. ${ }^{20}$

Similar distinción evidencia LeITe, al indicar que el principio de precaución se diferencia del principio de prevención, porque el primero exige adoptar medidas que reduzcan la posibilidad de sufrir daño ambiental grave a pesar de que se ignore la probabilidad precisa de que este ocurra, mientras que el principio de prevención obliga a tomar medidas dado que se conoce el daño ambiental que puede producirse. ${ }^{21}$

El medio ambiente también es un derecho de los trabajadores y en muchas ocasiones, su seguridad y salud están comprometidas por las condiciones ambientales en la empresa. Por ello, al tener un desempeño determinante en el modelo de desarrollo productivo, las medidas que se implementen sea que estas, estén destinadas a la prevención de daños ambientales efectivos o probables, serán más eficaces si cuentan con las herramientas jurídicas adecuadas para su protección.

\footnotetext{
${ }^{20}$ Costa, Ezio, "Principio de Precaución y Regulación Ambiental en Chile: Operando sin instrucciones, pero operando", Revista de Derecho Ambiental, 2014, № 6, p. 111.

${ }^{21}$ Leite, Augusto, "Protección del Medio Ambiente de Trabajo Según la Jurisprudencia Brasilera", Revista Chilena de Derecho del Trabajo y de la Seguridad Social, 2012, N5, pp. 34-35.
} 
Por ello, para hacer efectivo el papel de los trabajadores como sujetos activos de prevención, precaución, vigilancia y denuncia de posibles abusos medioambientales de sus empresas, resulta imprescindible la creación de una suerte de status y fuero especial de protección de dichos trabajadores, teniendo en cuenta no solo riesgos efectivos, sino también aquellos probables.

La adopción de medidas que suponen la integración entre trabajo y medio ambiente, contribuirían al cumplimiento de los compromisos que hemos adquirido frente al Derecho Internacional. Así, recordemos que según la Declaración de Rio del año 1992 (Río+10), sobre el Medio Ambiente y el Desarrollo, "los seres humanos constituyen el centro de las preocupaciones relacionadas con el desarrollo sostenible. Tienen derecho a una vida saludable y productiva en armonía con la naturaleza”. Asimismo, añade que "el derecho al desarrollo debe ejercerse en forma tal que responda equitativamente a las necesidades de desarrollo y ambientales de las generaciones presentes y futuras".

Por tanto, y conforme a la propia declaración, es preciso unificar un horizonte normativo entre medio ambiente y trabajo, entendiendo que ambos bienes jurídicos son igualmente susceptibles de protección dentro del espacio laboral, pero en el mismo espacio, sólo los trabajadores tienen la titularidad para defender ambos.

2. Derecho de resistencia frente a múltiples factores de riesgo interno y externo en la empresa

Desde sus albores, el Derecho del Trabajo se ha ocupado de regular y proteger a los trabajadores a razón de su participación en el proceso de desarrollo productivo, haciéndolos titulares de una serie de derechos y prerrogativas que surgen a propósito del contrato. La consideración del medio ambiente dentro del espacio laboral surge a partir de la necesaria protección de la salud de los trabajadores, acotándola generalmente a dos aspectos, en primer lugar, al espacio vital en que se desarrolla el trabajo y luego, a la función que realiza el trabajador en dicho espacio determinado. Estos dos elementos son considerados al determinar los eventuales riesgos a los que se podría ver expuesto un trabajador. Igualmente, y siguiendo a ESCRIBANO coincidimos con que el impacto del trabajo en el medio ambiente, se analiza mayoritariamente desde las nomas que tratan de evitar la exposición de los trabajadores a condiciones de trabajo insalubres a consecuencia del medio 
ambiente particularmente duro, alterado y degradado, en el que dicho trabajo se viene a desarrollar. ${ }^{22}$

En virtud de lo anterior, la calificación práctica de los riesgos se realiza por el empleador. Se trata de una decisión derivada de su poder de dirección y organización empresarial, que habitualmente está dotada de legalidad. Como se sabe, el punto de partida de esta cuestión se encuentra en la tradicional teoría del solve et repete. Conforme a ella, los trabajadores carecían de instrumentos adecuados para negarse, sin el aval de una resolución judicial, a acatar las órdenes emitidas por la empresa en el marco del ejercicio del poder de dirección.

Como contrapartida, y frente a órdenes empresariales arbitrarias o ilegales surge el derecho de resistencia. Este derecho se extiende no solo a las órdenes e instrucciones, sino también a todo el espectro de la relación laboral como una forma de defensa de los intereses legítimos y derechos propios del trabajador, alcanzando la exigencia del cumplimiento de las obligaciones que impone el contrato de trabajo. ${ }^{23}$

El derecho de resistencia de los trabajadores a las órdenes empresariales que sobrepasen los límites del poder de dirección empresarial se configura, desde nuestro punto de vista, como un importante instrumento de democratización de las relaciones de trabajo que, inevitablemente, chocan con la propia configuración jurídica de las mismas presididas por una fuerte jerarquización. ${ }^{24} \mathrm{~A}$ ello se suma la iniciativa económica privada reconocida constitucionalmente que deviene en el libre ejercicio de las actividades empresariales, lo que viene a suponer la capacidad de su titular para planificar los objetivos y estrategias de funcionamiento, así como para decidir los aspectos relativos a la combinación de los recursos humanos y medios materiales destinados a la producción. ${ }^{25}$

En el ámbito nacional, el derecho a resistencia o ius resistenciae ha sido esbozado fundamentalmente por nuestros Tribunales de Justicia al conocer demandas por despidos injustificados fundados en la causal de término de

\footnotetext{
${ }^{22}$ Escribano, cit. (n.13), p. 133.

${ }^{23}$ Domínguez, Álvaro; WALter, Rodolfo, "El despido disciplinario por incumplimiento grave de las obligaciones laborales en el ordenamiento jurídico chileno", Revista de Derecho Universidad de Concepción, 2017, Vol. 85, $N^{\circ}$ 241, pp. 27-28.

${ }^{24}$ Escribano, cit. (n. 14), p. 2.

${ }^{25}$ Morato, Rosa, Derecho de resistencia y ejercicio irregular del poder de dirección, Editorial Comares, Granada, 2011, p.1.
} 
contrato prevista en el artículo $160 \mathrm{~N}^{\circ} 4$ del Código del Trabajo, referidas al abandono de trabajo por parte del trabajador, en sus dos acepciones. ${ }^{26}$

Es preciso agregar que la doctrina reconoce como una manifestación legítima de dicho derecho, entre otras, las conductas de desobediencia por razones de seguridad, contenida actualmente en el artículo 184 bis del Código del Trabajo, incorporada a dicho texto por la Ley $\mathrm{N}^{\circ} 21.012$, la que consagra el derecho del trabajador de interrumpir sus labores y, de ser necesario, abandonar el lugar de trabajo cuando considere, por motivos razonables, que de continuar con aquellas actividades se produzca un riesgo grave o inminente para su vida o salud. ${ }^{27}$

Por su parte EscRIBANo sostiene que, para dotar a los trabajadores de un auténtico derecho de resistencia, habría de ser posible aplicar analógicamente los tres requisitos descritos por FALCON I TELLA en relación al derecho de desobediencia civil. ${ }^{28}$ Según esta autora, la desobediencia legítima ha de estar, en primer lugar, justificada en el plano de los valores. En concreto, e introduciendo ya la perspectiva medioambiental, la negativa de los trabajadores a acatar la orden empresarial estaría justificada en la protección del bien jurídico superior que es la preservación de una biosfera habitable. En segundo lugar, la desobediencia habría de ser explicada en el nivel de los hechos, es decir, no se trata del reconocimiento abstracto de un derecho, sino que está indisolublemente vinculado a su desarrollo práctico. Por último, tendría que ser excusada en el ámbito de las normas jurídicas, entendiendo por tal la imposibilidad de que la desobediencia genere reproche alguno. Desde el punto de vista de nuestra disciplina, esta falta de reproche se traduciría en la imposibilidad de que el empleador ponga en marcha sus exorbitantes facultades sancionadoras, particularmente el despido. La concurrencia de estos tres elementos genera, continuando con la elaborada teoría de FALCón I Tella, un derecho a la desobediencia civil en el contexto de una antinomia entre sujetos con intereses contrapuestos. Es evidente que esta antinomia se encuentra claramente presente en las relaciones sociales de producción.

Por ello, el ámbito de actuación del derecho de resistencia y, por

\footnotetext{
${ }^{26}$ Corte de Apelaciones de Antofagasta, 16 de febrero de 2015, Rol No 197-2014 y Corte de Apelaciones de Chillán, 12 de diciembre de 2013, Rol № 109-2013.

${ }^{27}$ Véase Dictamen de la Dirección del Trabajo, 14 de marzo de 2018, Ord. № 1366

${ }^{28}$ Escribano, cit. (n.14), p. 4.
} 
ende, la capacidad del trabajador para tutelar individualmente su integridad, queda circunscrito a un contexto determinado: a la concurrencia de un ambiente laboral o condiciones de trabajo que provocan un riesgo de severas magnitudes y de producción inmediata. ${ }^{29} \mathrm{La}$ amenaza puede también ser el resultado de cualquier otra circunstancia ajena a las obligaciones que en relación con el entorno y organización del trabajo le atañen, siempre que, y este es el elemento concluyente, se ponga de manifiesto en el desarrollo de la prestación de servicios de la que se ocupa el trabajador.

Por tanto, el origen del riesgo puede devenir de elementos directos o indirectamente asociados al proceso productivo y el contenido de la prestación, pero también no se descarta que el mismo pueda estar asociado con factores externos de la propia empresa. Puede inclusive, que tal calificación no está en un origen netamente atribuible a la conducta del empleador. Es posible, por ejemplo, que la situación de riesgo que soporta un trabajador se origine por circunstancias de procedencia externa causados por las labores desarrolladas en otros establecimientos colindantes o catástrofes naturales de tipo sísmico, volcánico, o inclusive la propagación de virus con alto nivel de contagiosidad, como la situación que vivimos actualmente a propósito del COVID-19, todas, circunstancias que tienen en común poner en riesgo la integridad y la vida de los trabajadores.

A modo de ejemplo y con ocasión del actual contexto sanitario, la procedencia externa de riesgos, que más tarde se hacen patentes al interior de los espacios laborales, ha motivado la reacción de las organizaciones sindicales encaminada a solicitar el resguardo de derechos fundamentales, particularmente el derecho a la vida, el que ha encontrado sustento en el otorgamiento de diversas medidas cautelares que han sido decretadas por los Juzgados Laborales a fin de mitigar o evitar situaciones de riesgo para los trabajadores.

Así, por ejemplo, uno de los primeros requerimientos que se formulan en el país con ocasión de la pandemia, se constata ante el Juzgado de Letras del Trabajo de Punta Arenas, en resolución dictada el día 06 de abril del año 2020, en causa RIT T-48-2020, que ordena suspensión de actividades productivas al interior de Supermercado Unimarc, frente a la denuncia presentada por el Sindicato de Trabajadores de la empresa Rendic Hnos S.A. quienes alzan su defensa invocando el 184 bis del C.T., frente a la falta

${ }^{29}$ Morato, cit. (n.25), p. 283. 
de condiciones sanitarias y medidas de prevención del COVID-19.

En el mismo sentido, el Juzgado de Letras del Trabajo de Concepción en causa RIT T-171-2020, suspende la obligación de los trabajadores afiliados al sindicato denunciante de concurrir a las faenas productivas de la empresa Madereras Arauco, sin menoscabo de sus remuneraciones, hasta que se obtenga de la Mutual a la que está afiliada la empresa, la determinación concreta y específica de las medidas de seguridad necesaria para asegurar la salud e integridad de los trabajadores; y esté certificada su implementación por dicho organismo. ${ }^{30}$

A razón de lo expuesto quedan en evidencia las indiscutibles conexiones que se sustancian entre medio ambiente de trabajo interno y externo. Del medio exterior que envuelve a la empresa pueden provenir riesgos que afectan a la seguridad de la población y, por supuesto, también a la de los ciudadanos en su condición de trabajadores. Mientras que, en sentido inverso, la promoción y mejora del medio ambiente-naturaleza no sólo comportará un evidente reflejo positivo en las condiciones de vida de los ciudadanos, sino también en las condiciones laborales de los trabajadores.

Por tanto, resulta del todo ineludible que el enfoque desde el que tratar los problemas de la seguridad y salud laboral se complemente con las cuestiones relativas a la seguridad medioambiental, quedando así integrados valores ecológicos en el sistema regulador de la seguridad e higiene en el trabajo. ${ }^{31}$

3. Finalidad y función de las organizaciones sindicales en el contexto chileno y comparado

Desde su génesis el movimiento obrero ha transitado por diversas etapas, en primera instancia se inicia con la negación de normas básicas de trabajo llegando hasta el reconocimiento de derechos laborales de corte colectivo que, habiendo descansado por largo tiempo en la ilegalidad, hoy son reconocidos como derechos humanos y como derechos fundamentales. Al respecto, es preciso indicar que, desde los orígenes del movimiento sindical, existen experiencias positivas, pero poco numerosas de las luchas

\footnotetext{
${ }^{30}$ Aguayo, Cristián, COVID-19. El derecho laboral en tiempos de pandemia, Thomson Reuters, Santiago, 2020, p.71

${ }^{31}$ Morato, cit. (n. 25), p. 287.
} 
obreras ecológicas, tales como la de los mineros en Río Tinto en Huelva y la resistencia de los mineros en las canteras de pizarra en Inglaterra durante el S. XX o las luchas de los trabajadores australianos de caña de azúcar en 1934. También los agricultores de Badajoz frente a la construcción de una refinería, la negativa de los estibadores vascos a descargar material para la construcción de una central nuclear en Lemóniz. ${ }^{32}$ Aquí en las luchas netamente de empresas, las reivindicaciones ambientales vienen también de la mano de la defensa de la salud laboral.

Tal proceso evolutivo del movimiento obrero según Palomeque, se construye sobre la concurrencia de tres elementos. El primero se refiere a la formación de la clase obrera y cuyo punto de partida arranca de la separación entre trabajador y los instrumentos o medios de producción. El segundo, es la aparición de este grupo social con conciencia de la condición obrera y, finalmente la convicción de la clase social diferenciada que, al estar desprovista históricamente de instrumentos políticos y legales capaces de modificar el status económico y social, concentra la idea de movilización contra el orden económico burgués, a través de organizaciones políticas y sindicales. ${ }^{33}$

Fruto del proceso evolutivo del movimiento obrero, sumado al reconocimiento internacional y nacional de los elementos propios de Libertad Sindical, tal derecho emerge como un instrumento de mediación en el conflicto social con afán de persecución de equilibro estructural entre los intereses de sus protagonistas. La administración y gobierno de los mencionados intereses comunes a cada una de estas categorías de personas ha propiciado la presencia de instancias representativas de los sujetos individuales de la relación laboral, cuya actuación se dirige a la consecución de una defensa más eficaz que la individualmente factible, de los intereses de cada trabajador. ${ }^{34}$

En este contexto, bajo el amparo de la libertad sindical se asume la defensa de los intereses de los afiliados, intereses que siendo más o menos comunes, se transforman en un interés colectivo capaz de elaborar escenarios idóneos que permitan a los trabajadores equilibrar la relación de trabajo, fomentar la cohesión social y democracia material, dado que

\footnotetext{
${ }^{32}$ Gari, Manuel, "Naturaleza, trabajo y sindicalismo”, en Mora y Escribano, cit. (n. 13), p. 180.

${ }^{33}$ Palomeque, Carlos, Trabajo e Ideología, Tecnos, Madrid, 2011, p.27.

${ }^{34}$ Palomeque, cit. (n. 33), p. 49.
} 
las organizaciones de trabajadores no representan únicamente intereses económicos, sino también intereses sociales, y desde esta perspectiva el papel de las organizaciones sindicales no se reduce a fijar condiciones de trabajo, sino que se convierte en un componente muy importante de la democracia material. ${ }^{35}$ En este sentido concordamos con quienes afirman de manera muy concluyente que hay ciertos derechos como la libertad sindical, huelga, seguridad social, que son juzgados básicos quizá porque, a pesar de su dimensión inmediatamente laboral, trascienden el puro ámbito del Derecho del Trabajo para contribuir a la definición de una forma más democrática de organización social y de distribución del poder en su seno. ${ }^{36}$

De este modo, la actividad del sindicato es una acción de regulación que impone reglas determinadas a la relación de trabajo. Actúa, por tanto, restringiendo y condicionando la libertad de la empresa en la contratación, la que se conoce como libertad de trabajo. El sindicato se confronta a una autoridad fuerte, la del empresario. Y esa autoridad se manifiesta en los lugares de producción fundamentalmente donde el empresario impone una organización de trabajo y las condiciones de prestación del mismo, que quieren ser reguladas por la acción del sindicato. Pero además las condiciones de trabajo tienen que ver con las condiciones de vida y de la existencia social de los trabajadores, por lo que al interés de estos se integra asimismo la protección frente a riesgos laborales, el desempleo, los estados de necesidad. El sindicato se proyecta en la esfera de lo social, no solo en la del mercado laboral o la de los lugares de producción. ${ }^{37}$ De este modo, la representación de intereses colectivos no es nominativa, el alcance de la acción sindical a la esfera de lo social, obliga a su desbordamiento desde que la acción sindical no se agota en la esfera redistributiva, sino en establecer condiciones de dignidad para los trabajadores.

Por tanto, el sindicato para cumplir sus fines -para ser útil- se despliega en el mercado (salario y tiempo de trabajo), en los lugares de producción de bienes y servicios (condiciones de trabajo) y en la esfera de lo políticosocial (condiciones de existencia, seguridad social). No solo se refiere en su

\footnotetext{
${ }^{35}$ VIllavicencio, Alfredo, La libertad sindical en las normas y pronunciamientos de la OIT: sindicación, negociación colectiva y huelga, Fundación de Cultura Universitaria, Montevideo, 2007, p. 13.

${ }^{36}$ Villavicencio, cit. (n. 35), p. 14.

${ }^{37}$ BAYLos, Antonio, ¿Para qué sirve un sindicato? Instrucciones de uso, Editorial Catarata, Madrid, 2012, p. 18.
} 
práctica a la cuestión salarial, sino al cambio en el modo de producir y a una existencia social en condiciones de dignidad y seguridad. ${ }^{38}$

Entre las características del interés colectivo, podemos mencionar su carácter indivisible, finalista y no instrumental y de naturaleza privada. ${ }^{39}$ Sin embargo, no coincidimos con una naturaleza esencialmente privada del interés colectivo en las relaciones laborales, toda vez, que la existencia de organizaciones sindicales de grado superior, muchas veces actúan influenciando las directrices de políticas públicas y leyes que pretenden establecer regulaciones, distanciándose de la atomización sindicatoempresa, que caracteriza la estructura sindical de primer orden o de base.

El carácter finalista del interés colectivo supone direccionar la acción sindical hacia los objetivos que le son propios. Al respecto nuestra legislación contempla en el artículo 220 del Código del Trabajo un extenso catálogo sobre los principales fines de las organizaciones sindicales, y entendemos que se trata de una enumeración meramente ejemplificadora. Por ello, es necesario tener en consideración que toda nuestra legislación sindical, por reglamentarista que sea, opera sobre una plataforma constitucional clara y definida: el principio de libertad sindical. ${ }^{40}$ Por tanto, las omisiones del legislador no son prohibiciones, más aún si implican una limitación a la libertad sindical. Todas las actividades sindicales son lícitas, si se enmarcan dentro de este principio, aunque el legislador no las contemple. ${ }^{41}$

La doctrina clasifica las finalidades sindicales en tres grupos: las de

\footnotetext{
${ }^{38}$ Baylos, cit. (n. 37), p. 19.

${ }^{39}$ Gamonal, Sergio, Derecho Colectivo del Trabajo, DER, 3ra. Edición, Santiago de Chile, 2020, p. 61.

${ }^{40}$ Gamonal, cit. (n. 39), pp. 120 y 122. En el mismo sentido: Arellano, Pablo, "Sistema de garantías y facilidades para el ejercicio de la función sindical: la función social" en: PALomo, R. (Coord.) $X X$ Jornadas Nacionales de Derecho del Trabajo y de la Seguridad Social, La organización sindical en Chile, Librotecnia, Santiago de Chile, 2015, p. 352.

${ }^{41}$ Fernández, Raúl, "Problemas derivados de la constitución de sindicatos con fines ilícitos: cuatro cuestiones discutidas", Revista Ius et Praxis, 2015, No 1, p. 378. "En la generalidad de los casos, los sindicatos se constituyen para lograr los fines que les son propios, siendo, en efecto, su constitución lícita, al perseguir objetivos admitidos, reconocidos, promovidos y protegidos por el ordenamiento jurídico, existe también la posibilidad que se constituyan con fines diversos, esto es, con fines totalmente ajenos a los que les son propios. Esto ocurrirá cuando en la constitución del sindicato se cumplan todos los requisitos formales establecidos en el Código del Trabajo, pero sus fines no sean sindicales, ya que no ha sido constituido con el propósito de defender los derechos e intereses de los trabajadores afiliados. Se trata de sindicatos formados al amparo de las normas legales que regulan el derecho de constituir organizaciones sindicales, siendo los mismos prima facie admitidos, pero se vulnera el espíritu y sentido de tales normas como también los valores y principios contemplados en normas legales de naturaleza imperativa. Son los sindicatos constituidos con abuso del derecho o en fraude a la ley".
} 
representación; de fiscalización, y de bienestar, asistencia, capacitación y otras. ${ }^{42}$ Sobre el punto, conviene tener en consideración la sinergia existente entre las finalidades sindicales y el quehacer ambiental, de modo que el sindicato pueda convertirse en un actor relevante a la luz de la autonomía que le es propia. En atención a ello, el escenario normativo compuesto por la legislación ambiental y la contribución de la jurisprudencia que habilita a los citados órganos intermedios para actuar como legitimarios activos en acciones destinadas a obtener la reparación del medio ambiente, ha podido insertarse dificultosamente en la jurisdicción ambiental, más no en el ámbito laboral.

Desde la creación de esta nueva jurisdicción, sólo constan tres demandas de reparación de daño ambiental incoadas por sindicatos independientes, encontrándose dos de ellas actualmente en tramitación. En primer lugar, constatamos la existencia de una demanda por reparación de daño ambiental, ante el Segundo Tribunal Ambiental, Rol D-30-2016, presentada por el sindicato de trabajadores independientes, pescadores artesanales, buzos mariscadores y ramas similares de Caleta Horcón y Caleta Ventanas contra Aes Gener S.A y Otros. ${ }^{43}$

La parte demandante funda la legitimación activa de su actuar en atención a que la acción de reparación de daño ambiental, posee legitimarios activos amplios, ya que el directamente afectado por el daño ambiental no es el que sufre el menoscabo en su patrimonio, sino el que sufre la pérdida de ese medio ambiente que le circunda.

En los hechos menciona que el Complejo Industrial Ventanas cuya existencia data desde 1964, se emplaza entre las comunas de Puchuncaví y Quintero. En este contexto ha sido calificado como uno de los polos industriales más grandes de Chile, en tal extensión geográfica actualmente encontramos la fundición y refinería de CODELCO, el complejo termoeléctrico de ventanas AES GENER, Central Termoeléctrica Quintero de ENDESA Chile, terminal GNL Quintero, ENAP refinería S.A, planta de lubricantes COPEC, entre otras.

Previo a la instalación del Complejo Industrial Ventanas (hace más de 50 años), las caletas de Horcón y Ventanas se habían dedicado a la pesca,

\footnotetext{
${ }^{42}$ Gamonal, cit. (n. 39), pp. 119 y ss.

${ }^{43}$ Causa Rol D-30-201 del Segundo Tribunal Ambiental. Causa cuyo ingreso data desde el día 1 de julio de 2016, actualmente en tramitación, etapa probatoria.
} 
buceo y recolección de mariscos, sumado a que la agricultura constituía una fuente laboral extra para los trabajadores de la pesca. La incorporación del Complejo Industrial Ventanas y el desarrollo industrial experimentado a lo largo de los años asilando empresas de diversos polos productivos trajo consigo, la contaminación del ecosistema marino, el aire y el suelo, a tal punto, que hoy nadie podría discutir que se trata de una "zona de sacrificio". El diagnóstico es lapidario, pues paralelo al desarrollo industrial de la mentada localidad, la actividad pesquera se encuentra amenazada y la agricultura prácticamente ha desaparecido, actualmente la causa se encuentra en tramitación.

Luego, ante el Tercer Tribunal Ambiental, Rol D-38-2018, ${ }^{44}$ presentada por la Federación de Sindicatos de Pescadores Artesanales de la comuna de Hualaihué contra Marine Harvest Chile S.A. En los hechos la Federación de Trabajadores demanda a la empresa dedicada al cultivo de salmones, por el escape de 9.000.000 de salmones en etapa de engorda, hecho que en efecto cadena, produce un desequilibrio en ríos y mares de la Isla Huar (ubicada cerca de Hualaihué) amenazando a las especies nativas marinas de la zona y afectando con ello a la pesca artesanal. No obstante, la demanda es rechazada por el citado Tribunal en atención a que la solicitud carece de justificación fundada en consideraciones medio ambientales que acrediten la inminencia de un perjuicio irreparable.

Finalmente, demanda por reparación de daño ambiental presentada ante el Tercer Tribunal Ambiental, Rol D-21-2016, por el Sindicato de trabajadores independientes de pescadores artesanales merlucero y afines Caleta Lo Rojas de Coronel y otros con Celulosa Arauco y Constitución S.A, Planta Horcones S.A. En la mentada causa los sindicatos de Talcahuano, Lota y Coronel no pudieron probar que las descargas de la celulosa al mar hayan generado daños a ecosistemas como los del río Itata y el Golfo de Arauco, descartándose además la responsabilidad de Nueva Aldea en la pérdida de bosque nativo y el daño a la biodiversidad, ya que CELCO no realiza actividades forestales. El rechazo de la demanda, motivó a la demandante a presentar recurso de casación en la forma y en el fondo, el que actualmente se encuentra en tramitación ante la Corte Suprema. ${ }^{45}$

Más allá del éxito o infortunio de las causas aludidas, las organizaciones

\footnotetext{
${ }^{44}$ Causa Rol D-38-2018 del Tercer Tribunal Ambiental.

${ }^{45}$ Corte Suprema, Causa Rol Civil N $11.558-2019$.
} 
lideradas por el sector de la pesca artesanal, hacen patente la compatibilidad entre acción sindical y medio ambiente, direccionada a la finalidad de asumir la representación del interés social comprometido por la inobservancia de las leyes de protección (garantía constitucional establecida en el art. 19 No8 de la Constitución Política de la República), establecidas en favor de sus afiliados, conjunta o separadamente de los servicios estatales respectivos. ${ }^{46}$ De este modo queda en evidencia que los sindicatos en representación de sus afiliados pudiesen accionar favorecidos por un interés ambiental de carácter supraindividual a causa de la infracción de normas ambientales que producen desprotección y afectan la salud de los afiliados y connaturalmente a la población que habita en los territorios afectados o adyacentes.

Del mismo modo, no resulta antojadizo que los representantes de las organizaciones de pescadores artesanales accionen ante los Tribunales Ambientales, desde que la pesca artesanal es el quinto sector más amenazado en Chile, ${ }^{47}$ particularmente en la zona centro y sur del país, a causa de las modificaciones que han experimentado los océanos y la sobreexplotación de recursos marinos.

De esta manera, algunas organizaciones sindicales han podido gestionar la custodia del medio ambiente, ante los Tribunales Ambientales $\mathrm{y}$, de paso, se han enmarcado en las finalidades legales para las cuales han sido creados, particularmente finalidades establecidas en el numeral 6 del artículo 220 del Código del Trabajo que fomenta la promoción de la educación gremial, técnica y general de sus asociados, se alza como vía idónea para realizar capacitaciones que promuevan la conciencia sobre el cuidado del medio ambiente, medida propuesta por la OIT, por el Programa $\mathrm{N}^{\circ} 21$ del PNUMA y por el principio N 10 de la Declaración de Río sobre Medio Ambiente y Desarrollo.

Igualmente, el numeral 7 del mismo texto legal, permite a los sindicatos canalizar inquietudes y necesidades de integración respecto de la empresa y su trabajo. A través de esta finalidad resultaría oportuno que los sindicatos pudiesen exponer sus alcances frente a la gestión ambiental de la empresa y generar propuestas destinadas crear o modificar espacios laborales más sostenibles, entendiéndolos como una extensión más, del medio ambiente en el que se desenvuelve todo ciudadano. La generación de propuestas

\footnotetext{
${ }^{46}$ Artículo 220 Nº 4 del Código del Trabajo.

${ }^{47}$ JAdRIEvich, Maritza, (Coord.), Plan Nacional de Adaptación al Cambio Climático, 2015, pp. 18-19.
} 
para estos efectos requerirá dotar a la organización de trabajadores de información relevante que les permita generar propuestas ambientales, sobre ello, trataremos más adelante.

Lo anterior refleja claramente que ordenamiento jurídico laboral, posee herramientas para que las organizaciones sindicales transiten hacia espacios laborales más ecológicos, pero para ello, resulta necesario que dichas organizaciones dejen de estar atomizados bajo el alero exclusivo de la empresa, y enmarcarse en un desafío de carácter nacional y global, que les permitirá mantener sus fuentes de empleo a largo plazo, mejorar la calidad de vida de sus afiliados y garantizar tales efectos para las futuras generaciones. Según Pérez Amorós, la dimensión supraestatal del medio ambiente, que no conoce fronteras, demanda una actuación sindical del mismo alcance. ${ }^{48}$

El favorecimiento de una actuación sindical protectora del medio ambiente, demanda una alianza estratégica con organizaciones no gubernamentales $(\mathrm{ONG})$, quienes han sostenido un rol protagónico en la protección del medio ambiente. Un análisis histórico sobre el surgimiento de las ONG ambientalistas, data con mayor relevancia a partir de los años 80 en nuestro país, tras el golpe militar y en medio del autoritarismo y fuertes restricciones al debate público el tema medio ambiental se convirtió en uno de los pocos espacios de disenso relativo, tolerados por la dictadura. ${ }^{49} \mathrm{Al}$ mismo tiempo, se debilitó la actuación sindical y se implementó una reforma que limitó fuertemente el libro que regulaba las relaciones colectivas de trabajo, por tanto, la imbricación entre ambos cuerpos intermedios no ha logrado una adecuada comunicabilidad, sea por el peso de la historia, sea por la existencia de intereses contrapuestos, que se posicionan antagónicamente cuando por razones ambientales se ordena el cierre de una empresa, y ello conlleva a la conclusión de fuentes de trabajo de quienes laboran para ellas.

No obstante, minoritariamente han existido alianzas exitosas, una muestra de ello se evidencia con la campaña denominada "Patagonia Sin Represas" que se alzó en contra de la construcción y asentamiento del proyecto Hidroaysén en la XI región, que buscaba construir dos centrales de en río Baker y tres en Río Pascua. Bajo los argumentos de mantener

48 Pérez, Francisco," Derecho del Trabajo y medio ambiente: unas notas introductorias", Gaceta Laboral, 2010, Vol. 16, N 1, p. 119.

${ }^{49}$ Ulianova, Olga y Estenssoro, Fernando, "El ambientalismo chileno: la emergencia y la inserción internacional", Si somos americanos, Revista de Estudios Transfronterizos, 2012, Vol. XII, N¹, p. 187. 
la belleza de los ecosistemas patagónicos de la región y la necesidad de preservarlos de manera prístina, se agruparon las más importantes ONG ambientalistas chilenas e internacionales, conjuntamente con organizaciones empresariales de la zona (cámara de turismo), ${ }^{50}$ trabajadores del sector turístico y empleados públicos agrupados bajo la Asociación Nacional de Empleados Fiscales (ANEF), logrando detener el asentamiento del proyecto.

En España, la integración medio ambiente-trabajo a la que nos hemos referido en párrafos anteriores se ha manifestado en sentido semejante en los más recientes documentos programáticos de organizaciones sindicales extranjeras como Solidaridad Obrera o el Sindicato Andaluz de Trabajadores que a su lucha sindical han sabido unir la lucha contra los cultivos transgénicos y la soberanía alimentaria de los pueblos. En el mismo sentido, la Confederación Alemana de Sindicatos (DGB) proclamó en su Congreso Confederal de 1972 que "el derecho a un medio ambiente adecuado para el ser humano es un derecho fundamental social. La política de medio ambiente es política social y no solamente un reto ecológico". ${ }^{51}$

Bugada explica que, en Francia la ambigüedad en la búsqueda de la transformación de la sociedad, tal vez explica, en parte, el retraso en la integración de las preocupaciones medioambientales en los principales sindicatos franceses. Durante mucho tiempo, este papel se delegará en el mundo asociativo y en la política. ${ }^{52}$

4. Derecho de información medioambiental en el ámbito del Derecho Colectivo

Atendido al enfoque de nuestro estudio, y la pertinencia del derecho a la información en esta materia, resulta preciso formular una distinción previa en torno a las dimensiones que adquiere el mentado derecho en las relaciones laborales individuales y colectivas. La composición de las normas asociadas al medio ambiente en la relación laboral (individual) entre empleador y trabajador, son más bien reactivas, vinculadas al deber de cuidado empresarial, y naturalmente, parten del supuesto de que toda

\footnotetext{
${ }^{50}$ Ibid., p. 208.

${ }^{51}$ Escribano, cit. (n.13), p. 145.

${ }^{52}$ Bugada, cit (n.16), p. 93.
} 
función laboral conlleva un riesgo, ${ }^{53}$ el soporte o mitigación de los mismos, será consorte del empleador a raíz de las consecuencias que se produzcan por su negligencia o falta de cuidado.

Por su parte, el modelo de relaciones colectivas construido y reformado en nuestro país, manteniendo la lógica reglamentarista, con acentuada intervención del Estado en cada uno de los elementos que componen la libertad sindical, ha propendido a la creación de un sistema de pesos y contrapesos que ha contribuido - en mayor o menor medida - a la búsqueda de equilibrios necesarios entre sus intervinientes.

En este esquema, "los contenidos posibles de la participación" de los trabajadores en la empresa se diferencian por una escala graduada de intensidad de los instrumentos diseñados por el ordenamiento laboral y los órganos titulares de tales mecanismos, distinguiéndose comúnmente tres niveles, bajo un criterio de "intensidad ascendente": la posibilidad de recibir y solicitar información al empresario para los trabajadores (derecho de información); la consulta que se debe realizar a los representantes de los trabajadores como requisito previo a la adopción de una decisión empresarial (derecho de consulta); y, finalmente, la cogestión o codecisión en la administración de la empresa (coadministración). ${ }^{54}$

De este modo el derecho de información es un derecho de naturaleza instrumental a la acción sindical colectiva, que constituye a su vez una libertad pública de dimensión prestacional, otorgando derechos y facultades a los representantes de los trabajadores para ser informados, informarse e informar sobre un conjunto determinado de hechos, datos o noticias relativas a la actividad económica, productiva, comercial y, en general, cualquier otra información sobre el giro y actividad de la empresa, que sea necesaria para

\footnotetext{
${ }^{53}$ En este sentido LANATA, Ruth Gabriela, Responsabilidad contractual y extracontractual por accidentes del trabajo y enfermedades profesionales, Cuadernos Jurídicos de la Academia Judicial, Ediciones DER, Santiago de Chile, 2019, p. 8: "Los empleadores tienen la obligación de informar oportuna y convenientemente a todos sus trabajadores acerca de los riesgos que entrañan sus labores, de las medidas preventivas y los métodos de trabajo correcto. Los riesgos son los inherentes a cada empresa".

"Especialmente deben informar a los trabajadores acerca de los elementos, productos y sustancias que deben utilizaren los procesos de producción o en su trabajo, sobre la identificación de estos (fórmula, sinónimo, aspecto, olor), sobre los límites de exposición permisible a estos productos, acerca de los peligros para la salud y sobre las medidas de control y de prevención que deben adoptar para evitar tales riesgos".

${ }^{54}$ Domínguez, Álvaro, “Análisis y crítica de la regulación del derecho de información de las organizaciones sindicales en Chile", Revista de Derecho Universidad de Concepción, 2016, № 239, p. 105.
} 
el sindicato para el ejercicio de su función representativa en un contexto de autotutela, control, consulta y negociación frente al ejercicio de los poderes empresariales, enmarcado en el contenido de la libertad sindical como derecho fundamental. ${ }^{55}$

Conviene mencionar que las principales tesis que se han postulado a este respecto pueden sistematizarse en torno a dos tendencias. Las que ubican la justificación de este derecho prioritariamente desde la perspectiva de los trabajadores (democracia industrial) y las que centran el enfoque en la perspectiva empresarial (función social del derecho de propiedad) ${ }^{56}$

El contenido esencialmente económico y financiero otorgado al derecho de información, no sólo obedece a un sistema reglamentarista, sino también, funciona como un límite y un correlato a la naturaleza de las obligaciones (de dar) que luego surgen, en un contrato colectivo. Según Domínguez, el legislador propone principalmente un modelo tasado y autoejecutable con plazos y oportunidades definidas, limitado a información de carácter económico y financiero circunscrito indirectamente a la negociación colectiva, renunciando a un modelo abierto general que permita un despliegue efectivo del derecho de información como facilidad instrumental de la función de representación. ${ }^{57}$

Asimismo, la ley 20.940 que modifica el derecho de información en las relaciones colectivas, ha dejado fuera, nuevamente informaciones de corte laboral y otras específicas que suelen contenerse en las legislaciones de otros países con sistemas laborales más avanzados. ${ }^{58}$ Así, por ejemplo, el art. 64.2 b) del Estatuto de los Trabajadores, reconoce el derecho del comité de empresa a ser informado de las actuaciones medioambientales, que tengan repercusión en el medio ambiente..$^{59}$ En nuestro país en cambio, las materias asociadas al medio ambiente de la empresa (iniciativa, elección y ejecución) continúan siendo una potestad exclusiva de la propietaria de la misma, materias que, a su vez están compuestas de un alto grado de voluntariedad que apelan a la responsabilidad social empresarial.

\footnotetext{
${ }^{55}$ Domínguez, cit. (n. 54), p. 105.

${ }^{56}$ Palomo, Rodrigo, "Modelo analítico del derecho de información de los representantes de los trabajadores y valoración de su reconocimiento en Chile", Revista Latinoamericana de Derecho Social, 2012, No 26, p. 124.

${ }^{57}$ Domínguez, cit. (n. 54), p. 121.

${ }^{58}$ Palomo cit. (n. 56), pp. 147-148.

${ }^{59}$ Escribano, cit. (n. 14), p. 19.
} 
Ahora bien, coincidimos con DomínGuez ${ }^{60}$ quien siguiendo a Monereo, afirma que la información constituye un instrumento que permite fundamentar la influencia del sindicato sobre la decisión patronal, y al mismo tiempo asegurar su autonomía sindical, en la medida que supone un conocimiento y posesión de datos precisos que hacen posible un control sobre la actividad empresarial, debiendo entenderse el derecho de información en una doble vertiente, esto es, no sólo como instrumento de democracia industrial, sino también como un soporte de la acción sindical, lo que da sustento a la concepción implícita del derecho de información, que no se agota en la formula explicita del mismo, ya que éste busca satisfacer el cumplimiento de las funciones y las finalidades dadas por el ordenamiento jurídico en el ejercicio de la libertad sindical. La diferencia vendrá dada frente a la fórmula tasada, puesto que esta última goza de garantías, plazos y oportunidades que facilitan su ejercicio oportuno.

Desde nuestro punto de vista, esta interpretación es acertada, dado que el carácter instrumental y coadyuvante del derecho a la información a la actividad sindical, constituye un suplemento nutricio para que las organizaciones sindicales puedan cumplir adecuadamente con las finalidades a las que están afectos. Entenderlo de otro modo, supondría que muchas de las finalidades enunciadas por el legislador en el art. 220 del Código del Trabajo, constituirán ejemplos desprovistos de ejecución, desde que se limita la actuación sindical conduciéndola hacía finalidades infértiles e inermes, inoperatividad jurídica que atenta directamente con la interpretación que debe darse a las instituciones que limitan la libertad sindical.

Más allá de nuestras concordancias interpretativas en torno al contenido implícito del derecho de información, no podemos desconocer, que una visión esencialmente tasada de la institución en comento, obligaría a realizar modificaciones legales que profundicen el contenido objetivo del derecho a la información, ampliándolo con el propósito de dar operatividad al actuar sindical para el cumplimiento de sus finalidades.

En uno u otro caso, la recepción de información de contenido medioambiental, permitiría que las organizaciones sindicales asuman un rol más relevante, teniendo una mayor participación en estas materias, desde que podrían no sólo formular iniciativas sino también participar en la ejecución de las mismas, o inclusive abstenerse de realizar determinadas

${ }^{60}$ Domínguez, cit. (n. 54), p. 135. 
acciones a fin de proteger el medio ambiente, dotando a los instrumentos colectivos de obligaciones que trasciendan a prestaciones exclusivamente económicas, para obtener beneficios que atiendan al interés general.

La amplitud del derecho de información a contenido ambiental, favorecería a la gestión sindical pero también contribuiría a un escenario idóneo para la aplicación y ejecución de principios que informan el Derecho Ambiental, particularmente con el principio de precautorio, el que si bien no está contenido en la Ley de Bases Generales del Medio Ambiente, se extrae de la Declaración de Río en su principio 15, reconocido en los términos siguientes: "Cuando haya peligro de daño grave e irreversible, la falta de certeza cientifica absoluta no deberá utilizarse como razón para postergar la adopción de medidas eficaces en función de los costos para impedir la degradación del medio ambiente".

Desde esta perspectiva, el principio precautorio impone una actuación anticipada, incluyendo las situaciones en que no se cuenta con la certeza absoluta de los efectos que un determinado hecho puede tener para el medio ambiente. Además, constituye un mandato de responsabilidad por la existencia, desarrollo y calidad de vida de las generaciones futuras. En efecto, la preocupación y responsabilidad respecto del desarrollo de las generaciones futuras es uno de los fundamentos del desarrollo sostenible, que tiene su base en el principio precautorio anticipadamente, aun frente a situaciones en que no existe certeza absoluta del daño, e incluso frente a una baja probabilidad del mismo, podrá garantizarse un medio ambiente adecuado para las posibilidades de supervivencia y desarrollo de las generaciones venideras. ${ }^{61}$

Un medio ambiente adecuado acarrea la necesidad de prevenir, remediar o cuando menos, aminorar los problemas que causan el deterioro medioambiental. Y es en este terreno de intervención, donde los trabajadores tienen un papel fundamental a desempeñar como sujetos relevantes de la actividad productiva, el desarrollo de medidas para estos fines debe contar ineludiblemente con su participación y colaboración, pues el éxito o el fracaso de las mismas depende de ello y de la información con que cuenten para direccionar sus finalidades.

Bajo el alero de nuestra propuesta y con el propósito de ampliar el

${ }^{61}$ Bermúdez, Jorge, Fundamentos de Derecho Ambiental, Ediciones Universitarias de Valparaíso, Valparaíso, Chile, 2014, $2^{\circ}$ Ed. Actualizada, pp.48-49. 
espectro de actuación de las organizaciones sindicales, resultaría oportuno que dicha materia pueda ser ampliada a fin de que las empresas puedan aportar información a los sindicatos sobre temáticas, tales como: 1) actuaciones empresariales mediatas o inmediatas que afecten al medio ambiente; 2) información sobre riesgos ambientales que afecten funciones determinadas dentro de la empresa; 3) medidas de prevención, mitigación o reparación del medio ambiente con ocasión de la actividad productiva que se desarrolla; 4) resultados obtenidos en auditorias de carácter ambiental que realice periódicamente la empresa; 5) iniciativas o propuestas que den mayor sostenibilidad a espacios laborales, etc. ${ }^{62}$

\section{Negociación colectiva y medio ambiente}

El Derecho Colectivo del Trabajo, ha sido entendido genéricamente como un derecho social, en el sentido de que sus normas positivas no buscan estatuir derechos mínimos, en cuanto contenido de las relaciones laborales; sino que establecen las reglas instrumentales por medio de las cuales los actores sociales, en uso de su autonomía colectiva determinan las condiciones de trabajo. ${ }^{63}$ Así se plasma en el artículo 306 del Código del Trabajo, norma que, al referirse a las materias de negociación colectiva, demarca contenidos de interés en las relaciones laborales, circunscritas a establecer condiciones comunes de trabajo.

Ahora bien, los cambios en los sistemas de negociación colectiva no suelen ser sólo el resultado de modificaciones del marco normativo que rige su desarrollo, sino también de alteraciones en las políticas y en las estrategias de los sujetos que la llevan a cabo, motivadas a su vez por cambios en el contexto económico y productivo en el que la misma ha de producirse. ${ }^{64}$

Para BAYLOS, la negociación colectiva es el instrumento idóneo para la anticipación y contratación de los cambios en la gestión de la empresa y

${ }^{62}$ El Consejo Federal de la Confederación Sindical de Comisiones Obreras ha venido incorporando desde 1992 en los criterios de negociación colectiva algunas propuestas relativas al medio ambiente y actualmente cuentan con un Eco Boletín que formula estudios y recomendaciones en torno a ecologizar los espacios laborales. Véase en: https://www.ccoo.es/Medio_Ambiente, 25 de febrero de 2020.

${ }^{63}$ Gamonal, Sergio, Trabajo y Derecho, AbeledoPerrot, Santiago de Chile, 2010, pp. 97-98.

${ }^{64}$ SAnguinEti, Wilfredo, "Los sistemas de negociación colectiva y sus transformaciones", en: TAPIA, Francisco (Coord.), Negociación Colectiva. Estudios en homenaje al profesor Emilio Morgado Valenzuela, Sociedad Chilena de Derecho del Trabajo y de la Seguridad Social, Ediciones On Demand, Chile, 2017, p. 509. 
de la co-determinación de aspectos importantes de sus decisiones en materia de empleo y de reparto del tiempo de trabajo y también todo lo que afecte a la salud en los lugares de trabajo. Por tanto, no tiene por qué reducirse al espacio marcado por la frontera del Estado-Nación. Al contrario, resulta obligado su desbordamiento. ${ }^{65}$ En el mismo sentido SANGUINETI, evidencia que la diversificación de los niveles de negociación viene acompañada por una ampliación manifiesta de los contenidos de los convenios colectivos que dejan de ser únicamente un instrumento para la fijación de salarios mínimos y jornadas máximas. ${ }^{66}$

El dinamismo del Derecho del Trabajo en general y de las relaciones colectivas en particular, supone la necesidad de dar respuesta a problemas novedosos en las relaciones laborales y en la gestión de trabajadores. Se trata de una función que puede calificarse como prelegislativa, y que hay que entenderla en el contexto de los procesos de transformación de las relaciones laborales y del mercado de trabajo, que requieren soluciones a medida que se van produciendo sin que la legislación laboral esté en condiciones de producir respuestas al ritmo requerido. ${ }^{67}$

En este contexto el derecho a la negociación colectiva posee, además una capacidad social transformadora que, en materia de medio ambiente está suponiendo un importante reto para el avance de nuestra sociedad hacia modelos laborales más sostenibles. ${ }^{68}$

Así las cosas, en el marco de una sociedad consciente, que comprende que la naturaleza posee límites físicos y que su renovación no se produce de modo proporcional a los ritmos de consumo, las materias ambientales deberían negociarse con la misma intensidad con que se negocian los ajustes salariales y la jornada laboral. La introducción de esta temática en los instrumentos colectivos, contribuiría a dotar a las iniciativas ambientelaborales de fuerza jurídica y coercitiva, a consecuencia del efecto normativo de los contratos colectivos y de las acciones que permiten asegurar su cumplimiento, con ello también se evita que tales materias queden sujetas

\footnotetext{
${ }^{65}$ BAYLos, Antonio, "El futuro de las normas del trabajo que queremos", en: Mora, L. y RodríGuEz, M. (Coords.), El futuro del trabajo que queremos, Editorial Bomarzo, Albacete, 2017, p. 132.

${ }^{66}$ SANGUineti, cit. (n. 64), p. 518.

${ }^{67}$ Rodríguez-PIÑEIro, Miguel, "El papel de la negociación colectiva. Contenidos a afrontar, aparición de nuevas actividades y nuevas formas de trabajo", Intervención de su autor en la XXX Jornada de estudio sobre negociación colectiva de la CCNCC, celebrada en Madrid, 26 de octubre de 2017.

${ }^{68}$ Chacartegui, cit. (n. 8), p. 19.
} 
exclusivamente a la Responsabilidad Social Corporativa de la Empresa.

A pesar de sus particularidades y de la observancia constante que se realiza a otros modelos de relaciones colectivas, particularmente europeos, lo cierto es que en nuestro país, una vez aceptada y extendida la negociación colectiva, este mecanismo se perfiló como un instrumento mucho más eficiente que la ley para regular las relaciones laborales, por las siguientes razones: 1) La negociación colectiva es pactada por los actores sociales, a saber empleadores y sindicatos, lo que permite que los acuerdos alcanzados se basen en la realidad social existente en el sector o empresa de que se trate, a diferencia de la ley que a veces ignora la realidad que desea regular; 2) La negociación colectiva es menos general que la ley, lo que facilita la consideración de factores particulares del ámbito al cual se va a aplicar; 3) La negociación colectiva es más flexible que la ley, lo cual permite que reaccione más rápido ante los cambios de circunstancias sociales o económicas; 4) Por lo tanto, la negociación colectiva posibilita elevar el nivel de vida de los trabajadores, utilizando un instrumento realista y flexible, que permite considerar las propias particularidades del sector o empresa donde se aplica. ${ }^{69}$

A razón de la caracterización que consta en el párrafo ut supra la negociación colectiva funciona como parte de una arteria que da vida a la libertad sindical, emergiendo como un componente contributivo a la prevención de conflictos laborales, y a la previsión de materias frente a las cuales el legislador se ha tornado silente. Naturalmente la velocidad a la que avanza la globalización modificando con ello las relaciones de trabajo, implica que el derecho muchas veces actúe de modo tardío.

Bajo este escenario, la autonomía colectiva y la capacidad de consensuar normas que incorporen en su contenido genético materias como el cuidado del medio ambiente, sea que, a través de ella, se acuerden acciones destinadas a su cuidado (obligaciones de hacer), o bien sea que se consientan acciones destinadas a no dañar el medio ambiente (no hacer), se mantendría el propósito de la negociación colectiva transitando a hacía finalidades con alcance ad intra y extra muros de la empresa. Sólo de este modo será posible superar el tradicional desajuste entre la conciencia de la clase obrera y la conciencia medioambiental, impuesta por el propio 
funcionamiento del actual sistema capitalista. ${ }^{70}$

Frente a la ausencia de instrumentos colectivos nacionales con contenido medio ambiental, nuevamente resulta oportuno mirar la experiencia comparada en la materia. Entiéndase que aquello se realiza, no para transponerlos directamente a nuestra realidad sindical, pero si para considerarlos en un sentido orientador. A modo de ejemplo, cabe indicar que a partir de la década del noventa en España los distintos congresos de la Unión General de Trabajadores (UGT) y las Comisiones Obreras (CC.OO), han venido incorporando aspectos relativos a la defensa del medio ambiente que, incluso, tienen reflejo en la propia estructura interna de dichas organizaciones sindicales. Para el caso de la UGT, su guía "el medio ambiente y los comités de empresa" del año 2001, vino a recoger la necesidad de que esta temática comenzará a tener reflejo en la negociación colectiva empresarial. En el mismo sentido CC.OO hizo pública en 1996 la Guía de acción medioambiental en las empresas, donde del mismo modo se planteaba la propuesta de que se incorporaran cláusulas medioambientales en los futuros contratos colectivos a negociar. ${ }^{71}$

Ya en 1972 la Confederación Internacional de Sindicatos Libres, en su declaración de la Conferencia de las Naciones Unidas en Estocolmo, manifestó: "Es en el entorno laboral donde surgen las condiciones que más tarde tendrán repercusión en el entorno exterior, esto se aplica a diferentes tipos de contaminación, que son en primer lugar un riesgo para la mano de obra que trabaja en la industria, pero que más tarde emergen como contaminación en el ambiente exterior". El diagnóstico anticipado de la mentada Confederación, clama de la actividad sindical la adopción medidas ecológicas en el terreno de la negociación colectiva, de manera que se vayan introduciendo en los contratos colectivos, cláusulas o compromisos de protección del medio ambiente, de prevención de impactos y riesgos, así como de información y control por parte de los representantes de los trabajadores.

\footnotetext{
${ }^{70}$ Olmo, Ana, "Tratamiento del empleo verde en la normativa internacional y europea (especialmente en el pilar europeo de los derechos sociales): la precisa reconfiguración de sus elementos jurídicolaborales", en Mora y Rodríguez, cit. (n. 59), p. 66.

${ }^{71}$ Escribano, cit. (n. 13), p. 144.
} 


\section{CONCLUSIONES}

El ordenamiento jurídico laboral no posee una regulación que armonice trabajo con medio ambiente. La literatura académica nacional ha sido escasa y la confabulación de ambos elementos, transita sobre bases etéreas que arrancan desde el Derecho Internacional del Trabajo, pero no se han asentado aún con la celeridad que se demanda. Sin duda hay una deuda pendiente.

En muchos aspectos, el medio ambiente reconfigura los antagonismos en torno a una causa más global, pero la temática puede resultar amenazante para trabajos que están mal preparados o son difíciles de adaptar a la transición ecológica. ${ }^{72}$

Frente a esta problemática que conjuga elementos (trabajo y medio ambiente) que a primera vista parecieran ser disímiles, adquiere sentido el rasgo ambivalente que caracteriza al Derecho del Trabajo, el que según BAYLOS, puede ser descrito como una expresión jurídica que deforma y condiciona las relaciones de producción basadas en la explotación de la fuerza de trabajo y a la vez enmienda y modifica el propio sistema capitalista, sin desnaturalizar su esencia. ${ }^{73}$ Bajo esta lógica hemos visto que, el modelo capitalista manteniendo sus cimientos, ofrece una alternativa para integrar trabajo y medio ambiente a través del desarrollo sostenible. A ello debemos adicionar las experiencias que entrega el derecho comparado en orden a replantear el funcionamiento de ciertos institutos del Derecho del Trabajo, como: derecho a la información, acción y finalidad sindical, negociación colectiva, entre otros. Y volcarlos hacia una mirada más integradora que permita a los sindicatos crear nuevas condiciones de producción acorde a los desafíos y problemáticas que actualmente aquejan al mundo del trabajo.

Lo anterior, no sin antes dotar de herramientas a los trabajadores y a las organizaciones sindicales a fin de que transiten hacia espacios laborales más ecológicos. Otras legislaciones como el Derecho Francés y el Derecho Español, ya han creado y adaptado instituciones propias del Derecho del Trabajo a una perspectiva ambiental, tal es el caso del derecho de resistencia,

\footnotetext{
${ }^{72}$ Bugada, cit. (n. 16), p. 93.

${ }^{73}$ BAylos, Antonio, "Modelos de Derecho del Trabajo y Cultura Jurídica del Trabajo", en BAYLos, G. (Coord.), Modelos de Derecho del Trabajo y Cultura de los Juristas, Editorial Bomarzo, Albacete, 2013, p. 16.
} 
el derecho de información y la negociación colectiva. Sin duda el uso de estos medios permitirá que los trabajadores logren enmarcarse en un desafío de carácter nacional y global, que contribuirá a mantener sus fuentes de empleo a largo plazo, mejorar la calidad de vida de sus afiliados y garantizar tales efectos para futuras generaciones.

Lo indicado hasta aquí tiene como finalidad la abertura a nuevos contenidos que obedecen a elementos propios de la contingencia y el dinamismo que caracteriza a las estructuras colectivas de tipo sindical. Así las cosas, la ubicuidad hacia una mirada biocéntrica satisface el propósito mismo del Derecho del Trabajo, propender a la dignidad del individuo, como ser inmerso dentro de un colectivo mayor, el planeta Tierra.

\section{BIBLIOGRAFÍA CITADA}

a) Doctrina y documentos citados

Aguayo, Cristián, "COVID-19. El Derecho Laboral en Tiempos de Pandemia” Thomson Reuters, Santiago, 2020.

Aguirrezabal, Maite. "Algunas precisiones en torno a los intereses supraindividuales (colectivos y difusos)". Revista chilena de derecho, 2006, $\mathrm{N}^{\circ} 1$.

Baylos, Antonio, Modelos de Derecho del Trabajo y Cultura de los Juristas, Editorial Bomarzo, Albacete, 2013.

Baylos, Antonio, ¿Para qué sirve un sindicato? Instrucciones de uso, Catarata, Madrid, 2012.

Bermejo, Roberto, "Equilibrio ecológico, crecimiento y empleo", en: La Roca, F. y SÁnchez, A., Economía critica, trabajo y medio ambiente, 1994, Fundaciód'estudis i iniciatives sociolaborals, Università de Valencià, España.

Bermúdez, Jorge, Fundamentos de Derecho Ambiental, Ediciones Universitarias de Valparaíso, 2014.

Bugada, Alex, Labour and Environmen tal Sustainability. French Report, Agreenment, 2020, http://agreenment.adapt.it/, consultada: 11 de Junio 2021.

Costa, Ezio, "Principio de Precaución y Regulación Ambiental en Chile: Operando sin instrucciones, pero operando", Revista de Derecho Ambiental, 2014, $\mathrm{N}^{\mathrm{o}} 6$.

Chacartegui, Consuelo, Negociación Colectiva y sostenibilidad medio ambiental, Editorial Bomarzo, Albacete, 2018.

Domínguez, Álvaro, "Análisis y crítica de la regulación del derecho de información de las organizaciones sindicales en Chile", Revista de Derecho Universidad de Concepción, 2016, Nº 239.

Domínguez, Álvaro, Walter, Rodolfo, "El despido disciplinario por 
incumplimiento grave de las obligaciones laborales en el ordenamiento jurídico chileno". Revista de Derecho Universidad de Concepción, 2017, № 241.

EsCRIBANo, Juan, "Derechos de los trabajadores ante las órdenes empresariales medioambientalmente injustas", Revista de Derecho Social, 2017, $N^{\circ} 78$.

FERNÁNDEZ, Raúl, "La constitución de sindicatos con fines ilícitos y sus efectos jurídicos en el derecho del trabajo chileno", Revista Ius et Praxis, Universidad de Talca, 2014, № 2 . 2020.

Gamonal, Sergio, Derecho Colectivo del Trabajo, DER, Santiago de Chile,

Gamonal, Sergio, Trabajo y Derecho, AbeledoPerrot, Santiago de Chile, 2010.

Jadrievich, Maritza, (Coord.), Plan Nacional de Adaptación al Cambio Climático, Santiago de Chile, 2015.

LANATA, Ruth Gabriela, Responsabilidad contractual y extracontractual por accidentes del trabajo y enfermedades profesionales, Ediciones DER, Santiago de Chile, 2019.

LANDER, Edgardo, "El lobo se viste con piel de cordero", Revista América Latina en movimiento, 2011, No 468-469, 2011.

LeITE, Augusto, "Protección del Medio Ambiente de Trabajo según la Jurisprudencia Brasilera", Revista Chilena de Derecho del Trabajo y de la Seguridad Social, 2012, №5.

LEÓN, Osvaldo, "Economía verde: la conciencia máxima del capitalismo", Revista América Latina en movimiento, 2011, II Ed., No 468-469.

Mora, Laura y escribano, Juan (Coords), La Ecología del Trabajo. El Trabajo que sostiene la Vida, Editorial Bomarzo, Albacete, 2015.

Mora, Laura y Rodríguez, María Luz (Coords.), El futuro del trabajo que queremos, Editorial Bomarzo, Albacete, 2015.

Morato, Rosa, Derecho de resistencia y ejercicio irregular del poder de dirección, Editorial Comares, Granada-España, 2011.

Organización Internacional del Trabajo, Trabajo y Cambio Climático: La iniciativa verde, Ginebra, 2017.

Organización Internacional del Trabajo, El desarrollo sostenible, el trabajo decente y los empleos verdes, Ginebra, 2013.

Palomeque, Carlos, Derecho del Trabajo e Ideología, Tecnos, Madrid, 2011, 7ma Ed.

Palomo, Rodrigo, "Modelo analítico del derecho de información de los representantes de los trabajadores y valoración de su reconocimiento en Chile", Revista Latinoamericana de Derecho Social, 2017, № 26.

Palomo, Rodrigo (Coord.), XX Jornadas Nacionales de Derecho del Trabajo y de la Seguridad Social, La organización sindical en Chile, Librotecnia, Santiago de Chile, 2015.

PÉrEZ, Francisco, "Derecho del Trabajo y medio ambiente: unas notas introductorias", Gaceta Laboral (Universidad de Zulia, Venezuela), 2010, V.16, №1. 
POLANYI, Karl, La gran transformación, Editorial Quipu, Madrid, 2007.

TAPIA, Francisco (Coord.), "Negociación Colectiva. Estudios en homenaje al Profesor Emilio Morgado Valenzuela”, Ediciones On Demand, Chile, 2017.

TISNE, Jorge, "Los intereses comprometidos en el daño ambiental: comentario al nuevo procedimiento por daño ambiental de la ley $\mathrm{n}^{\circ} 20.600$ ", Revista de Derecho Universidad Católica del Norte, 2014, Nº 1.

TISNE, Jorge, "Las organizaciones ciudadanas como representantes de intereses colectivos ambientales: Reconocimiento a través de la jurisprudencia chilena", Revista de Derecho P. Universidad Católica de Valparaíso, 2016, N46.

Ulianova, Olga; Estenssoro, Fernando, "El ambientalismo chileno: La emergencia y la inserción internacional”, Si Somos Americanos. Revista de Estudios Transfronterizos, 2012, No1.

VILLAVICENCIO, Alfredo, La libertadsindical en las normas y pronunciamientos de la OIT: sindicación, negociación colectiva y huelga, Fundación de Cultura Universitaria, Montevideo, 2007.

\section{b) Normativa}

Ley $N^{\circ} 19.300$ sobre Bases Generales del Medio Ambiente, 1994.

Ley $\mathrm{N}^{\mathrm{a}} 20.600$ que crea los Tribunales Ambientales, 2012.

Convenio OIT N ${ }^{0} 115$ sobre la protección contra las radiaciones, 1960.

Convenio OIT No 136 sobre la exposición de trabajadores al benceno, 1971.

Convenio OIT $\mathrm{N}^{\circ} 155$ sobre seguridad y salud de los trabajadores, 1981

Convenio OIT Nº162 sobre la exposición de trabajadores al asbesto, 1986.

Declaración de Río sobre el Medio Ambiente y el Desarrollo, 1992.

c) Jurisprudencia

Corte Suprema, Rol (Civil) N 11.558-2019.

Corte de Apelaciones de Antofagasta, 16 de febrero del año 2015, Rol No 197-2014. 2013.

Corte de Apelaciones de Chillán, 12 de diciembre del año 2013, Rol N 109-

Segundo Tribunal Ambiental, Rol D-30-2016 (causa actualmente en tramitación).

Tercer Tribunal Ambiental, 12 de septiembre del año 2018, Rol D-38-2018.

Juzgado de Letras del Trabajo de Punta Arenas, 06 de abril del año 2020, Rit T-48-2020.

Juzgado de Letras del Trabajo de Concepción, 26 de marzo del año 2020, Rit T-171-2020.

Dirección del Trabajo, 14 de marzo del 2018, Ord. № 1366. 